\title{
THE LUNG VOLUME AND ITS SUBDIVISIONS IN NORMAL BOYS 10-17 YEARS OF AGE ${ }^{1}$
}

\author{
By MINERVA MORSE, FREDERIC W. SCHLUTZ,2 AND DONALD E. CASSELS
}

(From the Department of Pediatrics, University of Chicago Clinics, Chicago, Ill.)

(Submitted for publication November 14, 1951 ; accepted February 5, 1952)

Data on the lung volume and its subdivisions were collected as part of a study of the functional fitness of normal boys 10-17 years of age (1). Since, in the case of children of all ages, so little is known concerning the total lung capacity and its subdivisions other than the vital capacity, the data are of value in helping to establish the range of variation in the normal child and to provide one basis for the evaluation of pulmonary function in disease.

Because the absolute values obtained have no meaning for children varying so greatly in size, except as they can be referred to some standard of reference, such as height, weight, and other measurements of body size, the results were analyzed by statistical methods in order to determine the relation of the lung volume and its subdivisions to various physical characteristics of the child. These relationships were then expressed in the form of regression equations which can be used to predict the lung volume and its subdivisions for a given individual and, by means of the standard error of estimate, can give a measure of the amount of variation that may be expected in the normal child.

Of the various subdivisions of the lung volume the vital capacity has been studied extensively in children and many formulae have been developed by which the "normal" vital capacity can be estimated from such measurements as standing or sitting height, weight, chest girth, surface area and combinations of these variables, some of which have included age. Metheny has given an excellent resumé of the literature on the subject $(2,3)$. A recent study by Turner and McLean (4) found that the mean inspiratory reserve constituted 76.0 per cent of the vital capacity and the expiratory reserve 24.0 per cent in children six to 14 years of age while in the recumbent position. Comparatively little is known about the total lung capacity

1 This work was conducted under a grant from the Douglas Smith Foundation at the University of Chicago.

2 Deceased March 8, 1944. and the residual volume. Robinson (5) studied the subdivisions of the lung volume for the whole age range from five to 91 years. His results were reported as absolute values and in terms of units of weight, height, and surface for various age groups, three of which fall within the age range of this study. His study was made before Lassen, Cournand, and Richards (6) suggested a modification of the closed-circuit method of Christie (7) for the determination of functional residual capacity, which would allow for an "oxygen storage" effect by including in the calculations nitrogen concentrations in alveolar samples taken at the beginning and end of the test.

\section{DEFINITION AND NOMENCLATURE}

The nomenclature recommended by a group of members of the American Physiological Society (8) has been used rather than other terms which have commonly appeared in the literature. According to this nomenclature, the inspiratory capacity is the maximum volume of air that can be taken into the lungs above the normal expiratory level, whereas the functional residual capacity is the volume of air left in the lungs after the normal expiration. The two together make up the total lung capacity. The expiratory reserve volume is the maximum volume of air that can be voluntarily expelled from the lungs after a normal expiration and the residual volume is the volume of air left in the lungs after the reserve volume has been expelled. The vital capacity is taken as the sum of the inspiratory capacity and the expiratory reserve volume. Ordinarily the latter determination followed immediately after the former. All terms used here refer to the resting, recumbent position.

\section{METHODS}

All measurements of the lung volume and its subdivisions were made in the recumbent position with one pillow under the head. The apparatus used for the lung volume determinations was a Sanborn closed-circuit wet spirometer with a kymographic drum and with the soda lime tube placed outside of the spirometer to reduce the dead space of the apparatus as recommended by Christie (7). Inspiratory capacity and expiratory reserve volume were calculated from the calibrated spirometric tracing after 2 line representing the normal expiratory level had been 
drawn. The maximum of three or four efforts was used. Volumes were corrected to $37^{\circ} \mathrm{C}$., saturated with water vapor (BTPS).

Following the recommendation of Hurtado and Boller (9), the residual volume was determined directly rather than the functional residual capacity. ${ }^{3}$ In other respects

3 The residual volume was determined directly, rather than the functional residual volume, in the hopes of reducing the error introduced in the calculation of the final spirometer level caused by irregular breathing. In many cases, however, the records showed poor agreement between the expiratory effort at the beginning and end of the test. Before calculating the residual volume each chart was studied carefully. The accuracy of calculation of oxygen consumption during the test was evaluated by comparing the rates of oxygen consumption in duplicate tests with each other and with that of a preliminary test made without forced expirations. The expiratory efforts at the beginning and end of the test were compared with each other and with the records of reserve air made during the preceding determination of vital capacity. Many inconsistencies were found. In each case a choice was made, whether to base calculations 1 ) on the final spirometer level measured after maximum expiration, 2) on a value calculated by subtracting oxygen consumption during the test from the spirometer level at the time the test began, or 3) on an average obtained by the two methods. Of 180 single determinations, 52 per cent were based upon method 3, 32 per cent upon method 2, and only 16 per cent upon method 1 . In case the record showed that the initial forced expiration was incomplete as compared to previous measurements, correction was made by reducing the calculated residual volume by the appropriate amount.

Measurements of residual volume were made on 94 individuals. In 85 of the cases it was possible to complete duplicate determinations. In 11 cases one of the duplicate values was discarded, usually because breathing was irregular and the expiratory effort inconsistent. The experimental error in the remaining 74 cases of duplicate determinations was calculated by the method described by Mainland (10) and used in a similar way by Herrald and McMichael (11), McMichael (12), Meneely and Kaltreider (13), and Gilson and Hugh-Jones (14). The results were as follows:

Sum of absolute differences

Mean difference $(5,902 / 74)$

Mean difference from mean of pairs

Sum of squares of absolute differences

Variance of absolute differences, 696,802/74

Standard deviation, $\sqrt{9,406}$

S.D. of differences from the mean, or,

S.E. of a single determination, $97.0 / \sqrt{2}$

S.E. of the mean of a pair of duplicates,

$$
68.6 / \sqrt{2}
$$

$5,902 \mathrm{ml}$.

$79.8 \mathrm{ml}$.

$39.9 \mathrm{ml}$.

$696,802 \mathrm{ml} .^{2}$

$9,406 \mathrm{ml}^{2}$ $\pm 97.0 \mathrm{ml}$.

$\pm 68.6 \mathrm{ml}$.

$\pm 48.5 \mathrm{ml} .^{2}$

For a mean residual volume of $698 \mathrm{ml}$., this represents a possible percentage error of \pm 19.6 per cent for a single determination, or \pm 13.8 per cent for the mean of a pair of duplicates, in 95 per cent of the cases. the method for the determination of the residual volume followed the modification of the closed-circuit method of Christie (7) which was suggested by Lassen, Cournand, and Richards (6). Unfortunately the study was begun before the preferable open-circuit method was described by Darling, Cournand, and Richards (15). At the end of a maximum forced expiration following a normal expiration (alveolar sample 1), the subject was connected to the spirometer containing a known amount of oxygen. After seven minutes of breathing through the closed circuit the test was terminated by another forced expiration (alveolar sample 2). The alveolar samples and samples taken from the spirometer were analyzed for nitrogen in a Haldane apparatus provided with a burette which was graduated between 5 and $10 \mathrm{ml}$. Residual volumes were calculated from the equation:

$$
V R=\frac{F^{\prime} S_{N_{2}} \cdot\left(V^{\prime} S+V D\right)-0.791 \mathrm{VD}}{-0.004 V S-V E_{N_{2}}} \times \frac{310}{273+A T} \cdot
$$

$\mathrm{VR}=$ residual volume at body temperature and ambient pressure, saturated with water vapor (BTPS).

$V D=$ dead space of apparatus, $2,260 \mathrm{ml}$. in this instance, as determined by the method of Christie (7). This value was maintained constant by keeping the spirometer filled with water up to a fixed point on the spirometer wall. By repeated rinsings the dead space was filled with room air before the test began.

VS = initial volume of the spirometer at ambient temperature and pressure (ATPS). The spirometer was filled with tank oxygen which contained 0.4 per cent nitrogen as an impurity.

V'S = final spirometer level (ATPS) if the final forced expiration was complete $=$ initial volume of spirometer minus oxygen consumed during the test.

$\mathrm{VE}_{\mathrm{N}_{2}}=$ volume of nitrogen excreted from the blood in seven minutes. This was calculated from a nomogram, based upon the data of Campbell and Hill (16), which related nitrogen excretion to rate of oxygen consumption and to spirometer nitrogen concentration.

$\mathrm{F}^{\prime} \mathrm{S}_{\mathrm{N}_{2}}=$ concentration of nitrogen in the spirometer at the end of the test.

$F A_{N_{2}}$ and $F^{\prime} A_{N_{2}}=$ concentrations of nitrogen in the alveolar samples taken before and after the test.

AT = ambient temperature.

0.791 = fractional nitrogen concentration in room air.

$0.004=$ fractional nitrogen concentration in tank oxygen.

$\frac{310}{273+A T}=$ factor for converting volumes obtained at ambient temperature to $37^{\circ} \mathrm{C}$.

\section{MATERIAL}

The subjects of the study were 124 normal healthy boys between the ages of 10 and 17 years, ${ }^{5}$ who participated in

Kindly given to the authors by Dr. Sid Robinson.

- We are indebted to the University of Chicago Settlement House, the Valentine Boy's Club, the Hyde Park Neighborhood House and friends for their kindness and interest in sending these boys to the laboratory for the tests. 
TABLE I

\begin{tabular}{|c|c|c|c|c|c|c|}
\hline \multicolumn{7}{|c|}{$\begin{array}{l}\text { Correlation coefficients which show the relation between the lung volume and its } \\
\text { subdivisions and certain physical characteristics }\end{array}$} \\
\hline $\begin{array}{l}\text { Independent } \\
\text { variable }\end{array}$ & $\begin{array}{l}\text { Total } \\
\text { lung } \\
\text { capacity }\end{array}$ & $\begin{array}{l}\text { Inspiratory } \\
\text { capacity }\end{array}$ & $\begin{array}{l}\text { Functional } \\
\text { residual } \\
\text { capacity }\end{array}$ & $\begin{array}{l}\text { Expiratory } \\
\text { reserve } \\
\text { volume }\end{array}$ & $\begin{array}{l}\text { Residual } \\
\text { volume }\end{array}$ & $\begin{array}{c}\text { Vital } \\
\text { capacity }\end{array}$ \\
\hline $\begin{array}{l}\text { Age } \\
\text { Height } \\
\text { (Height) } \\
\text { Actual weight } \\
\text { Normal weight } \\
\text { Surface area } \\
\text { Chest girth }\end{array}$ & $\begin{array}{l}.754 \\
.932 \\
.940 \\
.820 \\
.917 \\
.915 \\
.862\end{array}$ & $\begin{array}{l}.723 \\
.924 \\
.931 \\
.843 \\
.905 \\
.915 \\
.845\end{array}$ & $\begin{array}{l}.690 \\
.793 \\
.799 \\
.683 \\
.797 \\
.772 \\
.770\end{array}$ & $\begin{array}{l}.638 \\
.772 \\
.778 \\
.658 \\
.770 \\
.730 \\
.747\end{array}$ & $\begin{array}{l}.615 \\
.679 \\
.684 \\
.608 \\
.683 \\
.684 \\
.661\end{array}$ & $\begin{array}{l}.736 \\
.933 \\
.940 \\
.841 \\
.917 \\
.915 \\
.863\end{array}$ \\
\hline
\end{tabular}

the other tests for physical fitness which were described earlier (1). They came to the laboratory in the early morning and had rested one-half hour in the recumbent position before measurements of the lung volume and its subdivisions began. Total lung capacity and residual volume determinations were made in only 94 of the boys.

Certain physical characteristics of each boy were determined by methods described by McCloy (17), after all the tests in the recumbent position were completed. These included measurements of height, weight, chest circumference at the level of the xiphoid cartilage, hip (biiliac) width, knee width when flexed at a right angle, and skin and subcutaneous fat thicknesses measured by calipers over the chest, abdomen, back and hips (supra-iliac). Chest circumference was corrected for the presence or $a b-$ sence of subcutaneous fat. From such data the "normal weight," the "index of build," and the "index of fat," of each boy were calculated by the methods of McCloy (18). Surface area was estimated from height and weight by means of a nomogram (19) based on the formula of DuBois and DuBois (20).

\section{RESULTS}

As a basis for selecting the best physical characteristics to which individual lung volumes and cor- responding subdivisions could be referred, correlation coefficients between the lung volume and its subdivisions and certain physical characteristics were calculated (Table I). The results show that with few exceptions standing height serves somewhat better as a standard of reference than the more complicated measurements of surface or normal weight. In the case of residual volume and functional residual capacity slight preference might be given to normal weight. Age, actual weight and chest girth serve poorly as standards of reference. The higher correlations of the lung volume and its subdivisions with (height) ${ }^{3}$ as compared to those with the first power of height are to be expected in view of the three-dimensional character of the lung volume. On the basis of these results standing height was selected as the standard to which to refer the lung volumes found in this study. The mean values of the lung volume and its subdivisions which were found for these height groups are summarized in Table II.

TABLE II

The lung volume and its subdivisions, expressed as mean values and their standard deviations for successive height groups

\begin{tabular}{|c|c|c|c|c|c|c|c|}
\hline \multirow[b]{2}{*}{ No. of subjects } & \multirow[b]{2}{*}{ Height range } & \multirow[b]{2}{*}{$\begin{array}{l}\text { Total lung } \\
\text { capacity }\end{array}$} & \multicolumn{5}{|c|}{ Subdivisions of the lung volume } \\
\hline & & & $\begin{array}{l}\text { Inspiratory } \\
\text { capacity }\end{array}$ & $\begin{array}{l}\text { Functional } \\
\text { residual } \\
\text { capacity }\end{array}$ & $\begin{array}{l}\text { Residual } \\
\text { volume }\end{array}$ & $\begin{array}{l}\text { Expiratory } \\
\text { reserve volume }\end{array}$ & Vital capacity \\
\hline $\begin{array}{c}8(5) * \\
19(12) \\
13(11) \\
20(14) \\
12(8) \\
12(11) \\
16(13) \\
13(11) \\
6(5) \\
4(4) \\
1\end{array}$ & $\begin{array}{c}\mathrm{cm} . \\
137.5-142.4 \\
142.5-147.4 \\
147.5-152.4 \\
152.5-157.4 \\
157.5-162.4 \\
162.5-167.4 \\
167.5-172.4 \\
172.5-177.4 \\
177.5-182.4 \\
182.5-187.4 \\
190.0\end{array}$ & $\begin{array}{c}\mathrm{ml} . \\
2,738 \pm 122 \\
2,743 \pm 280 \\
3,124 \pm 352 \\
3,471 \pm 446 \\
3,776 \pm 491 \\
4,396 \pm 460 \\
4,594 \pm 306 \\
5,151 \pm 475 \\
5,640 \pm 529 \\
6,229 \pm 436\end{array}$ & $\begin{array}{c}\text { ml. } \\
1,654 \pm 118 \\
1,776 \pm 182 \\
2,008 \pm 277 \\
2,207 \pm 296 \\
2,438 \pm 334 \\
2,774 \pm 299 \\
3,033 \pm 351 \\
3,208 \pm 265 \\
3,612 \pm 434 \\
4,116 \pm 316 \\
4,290\end{array}$ & $\begin{array}{c}m l . \\
1,020 \pm 173 \\
1,008 \pm 190 \\
1,107 \pm 164 \\
1,279 \pm 292 \\
1,371 \pm 324 \\
1,616 \pm 290 \\
1,585 \pm 238 \\
1,893 \pm 377 \\
2,036 \pm 236 \\
2,113 \pm 325\end{array}$ & $\begin{array}{c}m l . \\
599 \pm 132 \\
492 \pm 155 \\
581 \pm 126 \\
675 \pm 201 \\
756 \pm 257 \\
880 \pm 229 \\
818 \pm 172 \\
1,048 \pm 273 \\
1,042 \pm 137 \\
1,132 \pm 300\end{array}$ & $\begin{array}{c}m l . \\
445 \pm 66 \\
525 \pm 104 \\
519 \pm 106 \\
623 \pm 134 \\
626 \pm 118 \\
725 \pm 149 \\
794 \pm 153 \\
830 \pm 135 \\
933 \pm 177 \\
981 \pm 78 \\
1,255\end{array}$ & $\begin{array}{c}m l . \\
2,099 \pm 129 \\
2,301 \pm 219 \\
2,527 \pm 331 \\
2,830 \pm 369 \\
3,064 \pm 362 \\
3,498 \pm 361 \\
3,826 \pm 377 \\
4,039 \pm 335 \\
4,545 \pm 447 \\
5,097 \pm 246 \\
5,545\end{array}$ \\
\hline
\end{tabular}

* Quantities in parentheses refer to the number of subjects in whom the residual volume was determined and the functional residual and total lung capacities calculated. 
A study of the mean volumes in relation to the corresponding mean heights showed deviations from a linear trend which suggested that the trend with increasing height might best be represented by a curvilinear function. "F" tests for non-linearity ${ }^{\circ}$ proved to be significant in the cases of the total, inspiratory and vital capacities, but gave no support for a non-linear relation to height in the case of the other subdivisions. The amount of individual variation is relatively greater in the case of the reserve, residual and functional residual vol-

- The F test for non-linearity is described by Goulden (21). It depends upon an analysis of variance after the data are set up in the form of a correlation table. The total sum of squares of deviations from the mean is split into two portions, one representing deviations of the means of the various arrays from the regression line, and the other representing differences between values within the arrays. The $F$ value represents the ratio between the variances due to these two factors. This is compared with the $F$ values which correspond to probabilities of 0.01 and .05 that the results are due to chance sampling. umes and therefore non-linearity of trend would be more difficult to prove. Since the correlations of all the subdivisions with (height) ${ }^{3}$ are higher than with height alone, and since the volumes under consideration are three-dimensional, we assumed that all of the volumes are better represented as a function of (height) ${ }^{3}$ and continued the analysis of the effect of other factors upon the lung volume and its subdivisions on that basis.

The high correlations of the lung volume and its subdivisions with the various physical characteristics of the growing boy are no doubt due to the fact that all of these measurements are linked with growth and that an increase in one measurement is more or less associated with similar increases in all of the others. To determine to what extent other factors act independently of (height) ${ }^{3}$ to determine the lung volume of an individual, partial correlation coefficients between the lung volume and its subdivisions and various physical characteristics were calculated, with (height) ${ }^{3}$ held

TABLE III

Partial correlation coefficients which relate the lung volume and its subdivisions to some physical characteristics of the subjects

\begin{tabular}{|c|c|c|c|c|c|c|}
\hline \multicolumn{7}{|c|}{ Variables held constant } \\
\hline \multirow{2}{*}{ Variable } & (height)? & $\begin{array}{l}\text { (height) } \\
\text { and index } \\
\text { of fat }\end{array}$ & $\begin{array}{l}\text { (height) } \\
\text { and chest } \\
\text { girth }\end{array}$ & (height)? & $\begin{array}{l}\text { (height) } \\
\text { and index } \\
\text { of fat }\end{array}$ & $\begin{array}{l}\text { (height) } \\
\text { and chest } \\
\text { girth }\end{array}$ \\
\hline & \multicolumn{3}{|c|}{ Inspiratory capacity and } & \multicolumn{3}{|c|}{ Total lung capacity and } \\
\hline \multirow[t]{2}{*}{$\begin{array}{l}\text { Age } \\
\text { Chest girth } \\
\text { Actual weight } \\
\text { Normal weight } \\
\text { Index of build } \\
\text { Index of fat }\end{array}$} & $\begin{array}{l}.021 \\
.302 \\
.239 \\
.263 \\
.268\end{array}$ & $\begin{array}{l}.296 \\
.264\end{array}$ & $\begin{array}{l}-.012 \\
-.048\end{array}$ & $\begin{array}{l}.158 \\
.431 \\
.196 \\
.355 \\
.374\end{array}$ & $\begin{array}{l}.491 \\
.462\end{array}$ & $\begin{array}{r}.026 \\
-.268\end{array}$ \\
\hline & \multicolumn{3}{|c|}{ Expiratory reserve volume and } & \multicolumn{3}{|c|}{ Vital capacity and } \\
\hline \multirow[t]{2}{*}{$\begin{array}{l}\text { Age } \\
\text { Chest girth } \\
\text { Actual weight } \\
\text { Normal weight } \\
\text { Index of build } \\
\text { Index of fat }\end{array}$} & $\begin{array}{r}.095 \\
.268 \\
-.030 \\
.185 \\
.140\end{array}$ & $\begin{array}{l}.390 \\
.289\end{array}$ & $\begin{array}{l}-.004 \\
-.350\end{array}$ & $\begin{array}{l}.051 \\
.378 \\
.198 \\
.308 \\
.293\end{array}$ & $\begin{array}{r}.417 \\
.349\end{array}$ & -.194 \\
\hline & \multicolumn{3}{|c|}{ Residual volume and } & \multicolumn{3}{|c|}{ Functional residual volume and } \\
\hline $\begin{array}{l}\text { Age } \\
\text { Chest girth } \\
\text { Actual weight } \\
\text { Normal weight } \\
\text { Index of build } \\
\text { Index of fat }\end{array}$ & $\begin{array}{l}.197 \\
.229 \\
.096 \\
.178 \\
.249\end{array}$ & $\begin{array}{l}.275 \\
.325\end{array}$ & $\begin{array}{r}.134 \\
-.174\end{array}$ & $\begin{array}{l}.205 \\
.320 \\
.053 \\
.246 \\
.300\end{array}$ & $\begin{array}{l}.418 \\
.418\end{array}$ & $\begin{array}{r}.115 \\
-.321\end{array}$ \\
\hline
\end{tabular}


statistically constant. Correlations with (height) ${ }^{3}$, with the various physical characteristics held constant, one or two at a time, were also calculated. In addition to the physical characteristics previously mentioned, all of which include the element of growth, two other characteristics, the index of build, and the index of fat, which are quite independent of the growth factor, were included in the statistical analysis. The results, summarized in Table III, allow the following deductions to be made :

1. With (height) ${ }^{3}$ held constant, correlations of the lung volume and all of its subdivisions with index of build or chest girth are high enough to be significant and are positive in sign. Thus the stocky boy with a relatively large thoracic crosssection tends to have a greater lung volume than the slender, narrow-chested boy of the same height.

2. With (height) ${ }^{3}$ and chest girth held constant, the correlation of the lung capacity with the index of fat is small but it is significant and is negative in sign. With (height) ${ }^{3}$ and index of fat held constant, the correlation of the lung capacity with the index of build or with chest girth is increased over its value with (height) ${ }^{3}$ alone constant. The same relationships hold for all of the subdivisions of the lung volume except the inspiratory capacity. The latter shows no significant correlation with the index of fat. The highest correlations with the index of fat pertain to the expiratory reserve volume and to the functional residual volume which contains it. This agrees with the finding of Aslett, Hart and McMichael (22) in adults, that an obese group had a substantially decreased relative expiratory reserve and a decreased functional residual capacity as compared with a non-obese group. Thus it appears that the presence of subcutaneous fat reduces the capacity for forced expiration, chiefly by reducing the resting lung volume, but it does not limit the inspiratory capacity.

3. With (height) ${ }^{3}$ held constant, the correlations of the lung volume and its subdivisions with normal weight are higher than those with actual weight. For a given height, a greater actual weight reflects a more stocky build, more subcutaneous fat or both. Since the former tends to increase the lung volume while the latter reduces it, poor correlations with actual weight could be expected.

4. The residual volume and functional residual capacity show a significant correlation with age when (height) ${ }^{3}$ is held constant, but the value of the correlation coefficient is reduced when chest girth is held constant with height. The correlation coefficient between total lung capacity and age, (height) ${ }^{3}$ held constant, is almost high enough to be considered significant, but is reduced almost to zero when chest girth is also held constant. Correlation coefficients between age and the other subdivisions of the lung volume are low and not significant, whether (height) ${ }^{3}$, or (height) ${ }^{3}$ and chest girth are held constant. The question of the effect of age upon the subdivisions of the lung volume will be discussed in greater detail later in this report.

By the method of least squares, regression equations were developed to express the relations between the lung volume and its subdivisions and the various standards of reference (Table IV). These may be used to predict the lung volume of boys between 10 and 17 years of age. The choice of which standard of reference to use will depend upon the availability of information on each physical characteristic and the accuracy of prediction gained by its use. Usually those physical characteristics which give the smallest error of prediction would be chosen as the appropriate standards, but for many purposes the slight gain in accuracy is overbalanced by practical considerations. Corresponding equations based on (height) ${ }^{3}$ and index of build or normal weight were not included in the table because it was found that they yielded no closer prediction than (height) ${ }^{3}$ and chest girth. Chest girth represents a direct measurement, whereas index of build and normal weight are calculated values which are based upon a number of body measurements, including chest girth.

Table IV includes simple linear equations based on height, for two height groups, 140 to $160 \mathrm{~cm}$., and 160 to $190 \mathrm{~cm}$. In this case a non-linear relation is expressed quite accurately by a series of linear equations covering smaller ranges of the independent variable. Linear equations offer the practical advantage of ease of calculation and for many purposes they are sufficiently accurate.

The relation of the subdivisions of the lung volume to the cube of the standing height represents one possible curvilinear function which has theorectical significance in that the lung volumes are three-dimensional. Another type of curvilinear relationship, represented by the equation $\log y=a+$ 
TABLE IV

\section{Regression equations which can be used to predict the lung volume and its subdivisions}

The relative accuracy of prediction and the normal range of variation can be estimated from the standard error of estimate since, theoretically, 95 per cent of the values for normal individuals of given physical characteristics will fall within \pm 2 standard errors from the value predicted from those characteristics by the use of the appropriate equation.

\begin{tabular}{cc}
\hline $\begin{array}{c}\text { Physical characteristics used as } \\
\text { standards of reference }\end{array}$ & Regression equation* \\
of estimate
\end{tabular}

Total lung capacity

\begin{tabular}{|c|c|c|}
\hline $\begin{array}{l}\text { Height (140-160 cm.) } \\
\text { Height (160-190 cm.) } \\
\text { Height and actual weight } \\
\text { (Height) } \\
\text { (Height) })^{2} \text { and actual weight } \\
\text { (Height) and chest girth } \\
\text { (Height) })^{2} \text {, chest girth, and index of fat }\end{array}$ & $\begin{array}{l}\mathbf{Y}=56.1 \mathrm{H}-5,272 \\
\mathbf{Y}=99.2 \mathrm{H}-12,120 \\
\mathrm{Y}=70.7 \mathrm{H}+11.4 \mathrm{AW}-7,930 \\
\mathbf{Y}=0.001035 \mathrm{H}^{3}-367 \\
\mathbf{Y}=0.000925 \mathrm{H}^{3}+10.2 \mathrm{AW}-412 \\
\mathbf{Y}=0.000796 \mathrm{H}^{3}+37.5 \mathrm{CG}-2,154 \\
\mathbf{Y}=0.000740 \mathrm{H}^{3}+46.3 \mathrm{CG}-284 \mathrm{IF}-2,273\end{array}$ & $\begin{array}{l}376 \\
369 \\
378 \\
363 \\
359 \\
328 \\
316\end{array}$ \\
\hline
\end{tabular}

Inspiratory capacity

Height (140-160 cm.)

Height (160-190 cm.)

Height and actual weight

(Height)

(Height) ${ }^{3}$ and actual weight

(Height) ${ }^{3}$ and chest girth

$\begin{array}{ll}\mathbf{Y}=40.3 \mathrm{H}-4,034 & 248 \\ \mathbf{Y}=64.0 \mathrm{H}-7,842 & 291 \\ \mathbf{Y}=43.7 \mathrm{H}+10.2 \mathrm{AW}-4,960 & 265 \\ \mathbf{Y}=0.000676 \mathrm{H}^{3}-297 & 265 \\ \mathbf{Y}=0.000570 \mathrm{H}^{3}+9.6 \mathrm{AW}-320 & 253 \\ \mathbf{Y}=0.000549 \mathrm{H}^{3}+19.4 \mathrm{CG}-1,202 & 248\end{array}$

Functional residual capacity

Height (140-160 cm.)

Height $(160-190 \mathrm{~cm}$.

$Y=19.7 \mathrm{H}-1,811$

$Y=32.9 \mathrm{H}-3,905$

$Y=25.6 \mathrm{H}+2.22 \mathrm{AW}-2,780$

$Y=0.000354 \mathrm{H}^{3}-50$

(Height)

(Height)' and chest girth

(Height) ${ }^{2}$, chest girth, and index of fat

$Y=0.000227 \mathrm{H}^{2}+19.8 \mathrm{CG}-993$

$\mathrm{Y}=0.000177 \mathrm{H}^{3}+27.6 \mathrm{CG}-253 \mathrm{IF}-1,099$

Vital capacity

Height $(140-160 \mathrm{~cm}$.

Height (160-190 cm.)

Height and actual weight

(Height)

(Height) and actual weight

(Height) and chest girth

(Height) ${ }^{3}$, chest girth, and index of fat

$\begin{array}{ll}\mathbf{Y}=49.2 \mathrm{H}-4,819 & 294 \\ \mathbf{Y}=79.9 \mathrm{H}-9,750 & 316 \\ \mathbf{Y}=56.2 \mathrm{H}+9.7 \mathrm{AW}-6,265 & 308 \\ \mathbf{Y}=0.000831 \mathrm{H}^{3}-266 & 297 \\ \mathbf{Y}=0.000731 \mathrm{H}^{2}+9.1 \mathrm{AW}-294 & 291 \\ \mathbf{Y}=0.000652 \mathrm{H}^{2}+27.5 \mathrm{CG}-1,559 & 275 \\ \mathbf{Y}=0.000616 \mathrm{H}^{3}+33.4 \mathrm{CG}-184 \mathrm{IF}-1,652 & 270\end{array}$

Expiratory reserve volume

Height $(140-160 \mathrm{~cm}$.

Height $(160-190 \mathrm{~cm}$.

Height and actual weight

(Height)

(Height) and chest girth

(Height) ${ }^{3}$, chest girth, and index of fat
$Y=8.9 \mathrm{H}-786$

$\mathrm{Y}=15.9 \mathrm{H}-1,914$

$Y=12.5 \mathrm{H}+0.5 \mathrm{AW}-1,304$

$\mathbf{Y}=0.000155 \mathrm{H}^{3}+25$

$y=0.000102 \mathrm{H}^{3}+8.13 \mathrm{CG}-357$

$\mathrm{Y}=0.000075 \mathrm{H}^{3}+12.7 \mathrm{CG}-143 \mathrm{IF}-429$
294

316

308

275

270

Residual volume

Height $(140-160 \mathrm{~cm}$.

Height (160-190 cm.)

Height and actual weight

(Height)

(Height) ${ }^{3}$ and chest girth

(Height) ${ }^{2}$, chest girth, and index of fat

$$
\begin{aligned}
& \mathbf{Y}=11.1 \mathrm{H}-1,055 \\
& \mathbf{Y}=16.7 \mathrm{H}-1,920 \\
& \mathbf{Y}=12.5 \mathrm{H}+2.91 \mathrm{AW}-1,385 \\
& \mathbf{Y}=0.000192 \mathrm{H}^{3}-45 \\
& \mathbf{Y}=0.000123 \mathrm{H}^{2}+10.9 \mathrm{CG}-567 \\
& \mathbf{Y}=0.000101 \mathrm{H}^{2}+14.3 \mathrm{CG}-109 \mathrm{IF}-612
\end{aligned}
$$

112

134

125

123

119

111

* The constants of the regression equations are based upon the following units of measurement: The lung volume and its subdivisions, $\mathrm{ml}$.; height and chest girth, $\mathrm{cm}$.; actual weight, $\mathrm{Kg}$. 


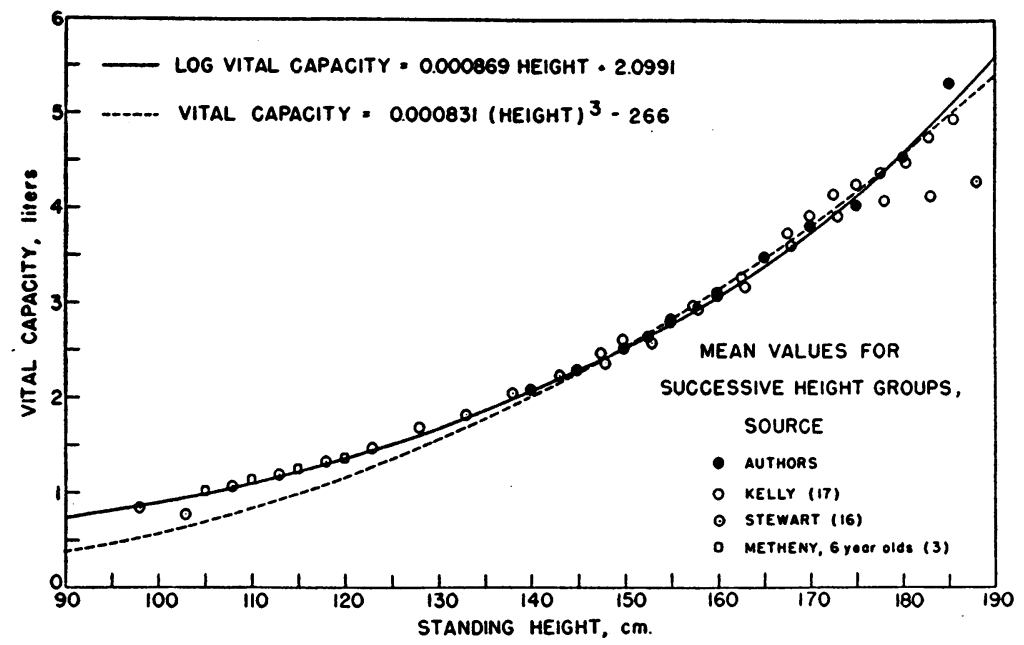

Fig. 1. A Comparison of the Semi-Logarithmic Curve with One Based on (Height) ${ }^{3}$ as a Means of Expressing the Relation of Vital Capacity to Standing Height throughout Childhood and Adolescence

The plotted points represent mean values for successive height groups taken from studies by Stewart (23), Kelly (24), Metheny (3), and the authors.

bx, was also investigated. This equation is the integral form of the differential equation, $\frac{d y}{d x}=b y$. It has theoretical foundation since it is a fundamental expression of growth. If $y$ and $x$ represent lung volume and height, respectively, this equation would mean that an increase in lung volume due to an increase in height is a constant function of the lung volume existing at the moment. The curves of Figure 1 illustrate the two curvilinear relationships, semi-logarithmic and cubic, between vital capacity and height. Vital capacity was chosen as an example because more data from previous studies by other investigators are available for comparison. The curves were continued downward to the left, below the height range of the boys in the present study, to include standing heights as low as might be expected of young children old enough to cooperate in the test, for the purpose of testing, by comparison with the results of other investigators, whether either of the two curves were applicable to younger children. Two extensive studies of children by Stewart (23) and by Kelly (24) and a study of children three to six years of age by Metheny (3) were selected from the literature for comparison with the authors' data. In Figure 1 the mean values of vital capacity for the various height groups have been superimposed upon the regression curves which were fitted to the authors' data for boys of 10 to 17 years by the method of least squares.

Within the height range upon which the regression equations were based, $140-190 \mathrm{~cm}$., the mean values of vital capacity found by Stewart and by Kelly for successive height groups agree well with either regression curve. Below this height range the curves separate. With few exceptions the mean values found by Stewart for younger children and those found by Metheny for six-year-olds agree well with the semi-logarithmic curve. The equation based on (height) ${ }^{3}$ appears to give values that are too low in the height range below $140 \mathrm{~cm}$. From a study of pre-school children, Metheny found that for a given height vital capacity increased with age. Mean values for children younger than six years would therefore lie below the semi-logarithmic curve. A recent study by Turner and McLean (4) gives values for the vital capacity of young children that lie for the most part above either curve.

The semi-logarithmic relations of the other subdivisions of the lung volume to standing height were also investigated. It was found that the correlation coefficients between height and the logarithms of the subdivisions of the lung volume tend to be slightly lower than those between height 
and the non-logarithmic values and therefore add nothing to accuracy of prediction within the height range studied.

In the case of adults the relative proportions of the total lung capacity occupied by the different subdivisions have been shown to be more constant than the absolute volumes of the subdivisions $(9,22,25$ 29). For the children of this study mean values for successive age groups, as well as the overall mean values for each subdivision, are given in Table $\mathrm{V}$ as percentages of the total lung capacity. For the group as a whole the various subdivisions show the following coefficients of variation: inspiratory capacity, 7.7 per cent; functional residual capacity, 13.6 per cent; residual volume, 22.9 per cent; expiratory reserve volume, 16.2 per cent; and vital capacity, 5.4 per cent. These values are only slightly lower than the corresponding coefficients of variation for the absolute volumes, which are obtained by referring the lowest standard error of estimate for each subdivision to the appropriate mean value for the whole group, 9.8, 16.0, 24.4, 16.5 and 8.5 per cent, respectively.

The data show no consistent change in the relative volumes of the various subdivisions which may be attributed to age. However, at 13 years and again at 15 years the functional residual capacity appears to occupy a smaller fraction of the total lung volume, due both to lower residual and expiratory reserve fractions. Some of the age differences are high enough to be statistically significant, for " $t$ " values of 2.38, 2.85 and 2.33 were found for the decrease in functional residual capacity between 12 and 13 years, its increase between 13 and 14 years and its subsequent fall between 14 and 15 years, respectively. The decrease in the relative volume of the expiratory reserve between 14 and 15 years was also significant, with a " $t$ " value of 3.44. Other differences are less significant and are more likely the result of chance sampling. ${ }^{\text {? }}$

Because of the apparent differences in the relative proportions of the subdivisions of the lung volume at 13 and 15 years, the effect of age upon the absolute volumes was investigated further. Figure 2 shows the distribution by age of the deviations of the determined values from those predicted from the (height) ${ }^{8}$, chest girth and index of fat of each boy. The chart shows that certain boys of 13,14 and 15 years had lower total lung capacities than were found in both younger and older boys and that in the case of the 14-year-old boys the lower lung capacity was related to a lower inspiratory capacity, while in the 13- and 14-year-old boys it was due largely to lower expiratory reserve and residual volumes. The data of Robin-

7 The effect of the large experimental error which occurs in the determination of these volumes was considered in this connection. In the case of the residual volumes data from duplicate determinations are available and an estimation of the effect of the experimental error can therefore be gained by statistical analysis of variance (30). The greatest difference in the mean relative residual volume, 2.9 per cent units, was found between the 13- and 14-year-old groups. Although this difference did not prove to be significant because of the large individual variation, an analysis of variance was made in order to evaluate the relative effect of experimental and sampling errors. The 13- and 14year-old groups included the results of duplicate determinations on 14 and 15 individuals respectively. The variance between groups was found to be 104.5, and that within groups was 44.6 , while the variance between the results for duplicate determinations was 5.3. Thus, only a comparatively small portion of the large variance within groups can be attributed to the error of the technique.

TABLE $\mathbf{v}$

Mean values of the subdivisions of the lung volume, expressed as percentages of the total lung capacity, for successive age groups from 11 to 17 years

\begin{tabular}{|c|c|c|c|c|c|c|}
\hline Age & $\begin{array}{l}\text { No. of } \\
\text { cases }\end{array}$ & $\begin{array}{l}\text { Inspiratory } \\
\text { capacity }\end{array}$ & $\begin{array}{l}\text { Functional residual } \\
\text { capacity }\end{array}$ & Residual volume & $\begin{array}{c}\text { Expiratory reserve } \\
\text { volume }\end{array}$ & Vital capacity \\
\hline $\begin{array}{l}y r s . \\
11 \\
12 \\
13 \\
14 \\
15 \\
16 \\
17\end{array}$ & $\begin{array}{r}8 \\
8 \\
16 \\
20 \\
23 \\
13 \\
5\end{array}$ & $\begin{array}{c}\text { per cent } \\
63.9 \pm 0.8^{*} \\
61.6 \pm 1.9 \\
66.7 \pm 1.2 \\
62.0 \pm 1.1 \\
65.4 \pm 0.9 \\
62.7 \pm 1.6 \\
62.8 \pm 1.3\end{array}$ & $\begin{array}{c}\text { per cent } \\
36.1 \pm 0.8 \\
38.5 \pm 1.9 \\
33.3 \pm 1.2 \\
38.0 \pm 1.1 \\
34.6 \pm 0.9 \\
37.3 \pm 1.6 \\
37.2 \pm 1.3\end{array}$ & $\begin{array}{c}\text { per cent } \\
17.9 \pm 1.4 \\
20.4 \pm 2.0 \\
17.0 \pm 1.0 \\
19.9 \pm 1.0 \\
18.9 \pm 0.8 \\
20.5 \pm 1.4 \\
19.3 \pm 1.3\end{array}$ & $\begin{array}{c}\text { per cent } \\
18.2 \pm 1.1 \\
18.1 \pm 1.3 \\
16.3 \pm 0.7 \\
18.1 \pm 0.4 \\
15.7 \pm 0.4 \\
16.8 \pm 0.4 \\
17.8 \pm 0.6\end{array}$ & $\begin{array}{c}\text { per cent } \\
82.1 \pm 1.4 \\
79.6 \pm 2.0 \\
83.0 \pm 1.0 \\
80.1 \pm 0.8 \\
81.1 \pm 0.8 \\
79.5 \pm 1.4 \\
80.7 \pm 1.3\end{array}$ \\
\hline $11-17$ & 93 & $63.9 \pm 0.5$ & $36.1 \pm 0.5$ & $19.1 \pm 0.5$ & $17.0 \pm 0.3$ & $80.9 \pm 0.5$ \\
\hline
\end{tabular}

* The figures following the \pm signs represent the standard error of the mean. 

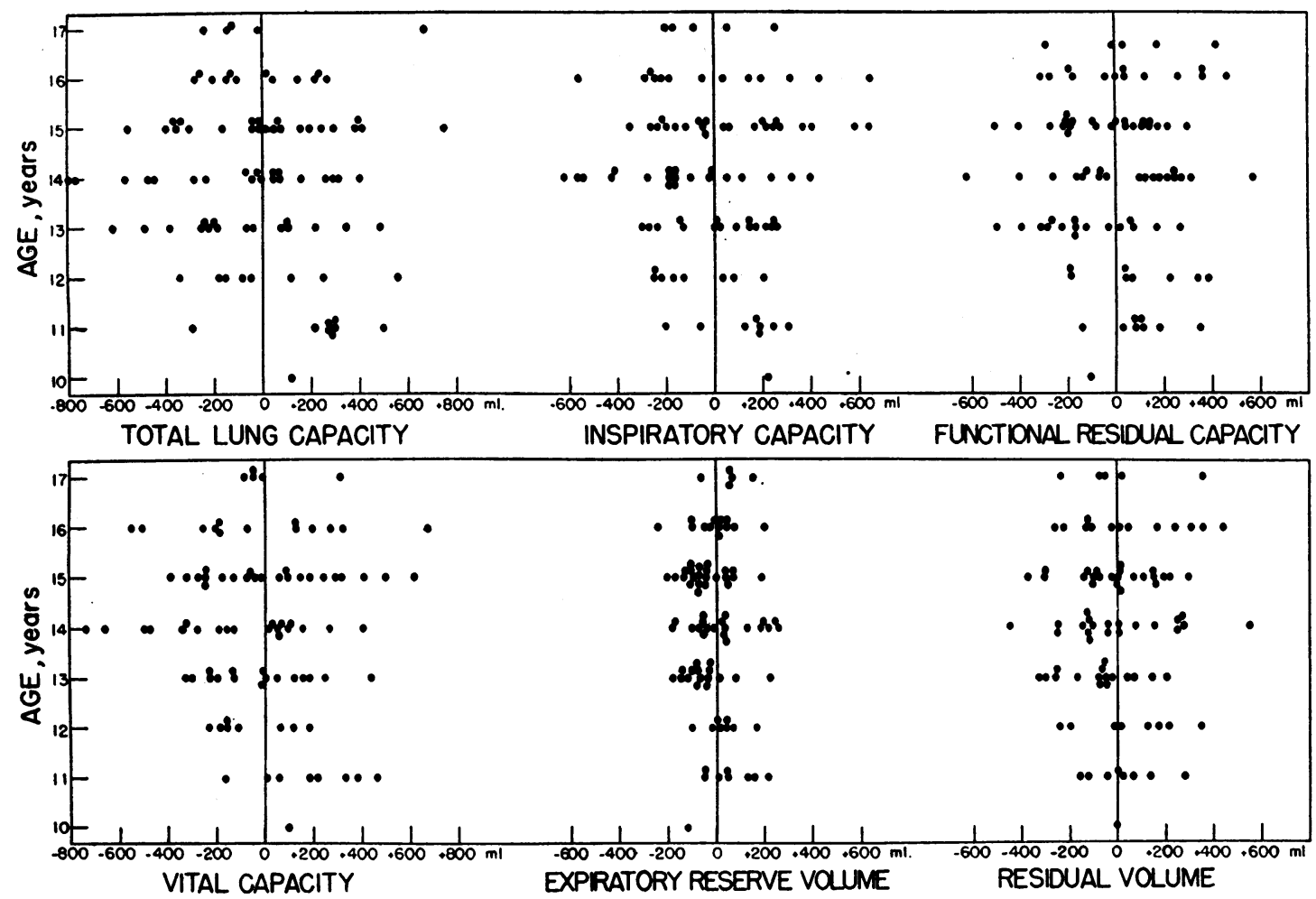

Fig. 2. Distributions of the Deviations of the Lung Volumes Found from Those Predicted from the (Height $)^{8}$, Chest Girth, and Index of Fat of Each Individual, Plotted According to Age

son (5) also give evidence of an age effect upon the lung volume during puberty, since lower values were found for the total lung volume of the 15year-old group as compared with those of the 10.5- and 17-year-old groups when the volumes were referred to-a unit of body weight.

Kelly (24) found an effect of age or maturity in addition to those effects represented by (height) ${ }^{3}$ and body weight when she determined partial correlation coefficients for vital capacity data from almost 4,000 boys between 12 and 18 years of age. Since the calculation of partial correlation coefficients from our data for boys 10 to 17 years of age showed no significant effect of age upon the vital capacity, apart from its effect upon body height and chest girth, it seemed possible that with this particular age range a decreasing effect associated with puberty may have masked a later maturing effect. Partial correlation coefficients were recalculated, omitting data for boys under 12 years in order to approximate the age range studied by Kelly. For the age range between 12 and 17 years the partial correlation between vital capacity and age, with (height) ${ }^{3}$ held constant, was found to be 0.1830 , a value high enough to be almost significant at the 5 per cent level $(t=1.93)$, but with chest girth held constant in addition to (height) ${ }^{3}$ the correlation coefficient between vital capacity and age was reduced to 0.0038 . Similar correlation coefficients between vital capacity, with (height) ${ }^{3}$ and actual or normal weight held constant, were 0.1067 and 0.0084 , respectively, and were therefore not significant.

\section{DISCUSSION}

Although body surface has sometimes been used as a standard of reference for purposes of estimating the normal vital capacity of an individual, standing height is now more commonly preferred. The use of (height) ${ }^{3}$ was first suggested by Kelly (24) for the prediction of vital capacity and recently was advocated by Bateman (29) as a basis for the calculation of normal values for the total lung capacity and its other subdivisions. The present study gives further proof of its usefulness. 
It is generally recognized that less variability is encountered when the volumes of the various subdivisions are expressed as percentages of the total lung capacity $(9,22,25-29)$. By means of multiple regression equations containing (height) ${ }^{3}$ and one or more other physical characteristics as variables it is possible to estimate absolute values which approximate relative values in accuracy. While statistical analysis of our data has given evidence of the predictive value of such multiple regression equations, it must be admitted that the individual values found for normal boys still deviate considerably from the calculated value, even when the best combination of physical characteristics is used. McCloy recognized this in his study of the vital capacity (18). The present results show that it is still more true of the other subdivisions of the lung volume.

Although individual anatomic, functional and psychological factors undoubtedly contribute to this variability, it is true also that errors in the methods used are comparatively large, even when all precautions are taken to insure accuracy. Vital capacity determinations are reasonably accurate, although proof of maximum effort is not entirely certain in many cases, especially in younger children. Separation of the vital capacity into two components, the inspiratory capacity and the expiratory reserve volume, depends upon determining the normal expiratory level. In the case of irregular breathing considerable error may be introduced in the measurement. Errors in the determination of the functional residual or the residual volume by the closed circuit are even greater. Since this study was begun a number of improvements have been introduced to eliminate some sources of error (11-13, 31, 32). The open-circuit method introduced by Darling, Cournand and Richards (15), however, appears to allow fewer sources of error. It is hoped that this method may be applied to a further study of the lung volume in children.

Except for the vital capacity, which has been studied extensively, little information is available in the literature by which we may evaluate our results. The data of Robinson (5) are based upon an earlier modification of the closed-circuit method and are not therefore strictly comparable as regards the total lung capacity and those subdivisions which include the residual volume. Compared with val- ues predicted from the mean height and weight of those age groups which fall within the age range of our study, Robinson found slightly higher values for all of the subdivisions of the lung volume, with deviations above the predicted values at 14 years of 64,102 , and $116 \mathrm{ml}$. for inspiratory capacity, expiratory reserve and residual volumes, respectively. Lung volume studies of normal adults using the open-circuit method (28) or various modifications of the closed-circuit method (9, $22,25-27,32-34$ ) cannot be compared with our data for boys because of the effect of age upon the various subdivisions and because in most cases the tests were conducted in the sitting posture (22, 27-29).

The question whether or not age exerts an effect upon the lung volume of the boy, apart from its effect upon body height and chest girth, during the years from 10 to 17 years cannot be answered conclusively from the results of this study. In the case of the vital capacity, Kelly's finding (24) of a significant correlation with age when (height) ${ }^{3}$ and weight were held constant is contrary to the results of the present study which showed no significant correlation between vital capacity and age when (height) ${ }^{3}$ and chest girth or weight were held constant. With data from comparatively few cases, as in the present study, the error due to chance sampling is greater. The indication that boys of 13,14 , and 15 years of age tend to have smaller lung volumes for a given (height) ${ }^{3}$, chest girth and index of fat also raises the question of non-linearity of trend with age and the possibility of errors in the statistical analysis due to that source.

\section{SUMMARY}

The inspiratory capacity and the expiratory reserve volume in the resting recumbent state were determined by spirometric methods in 124 normal healthy boys of 10 to 17 years. In addition the residual lung volume was determined in 94 of these boys by the Lassen modification of the closed-circuit, oxygen dilution method of Christie. From these measurements the total lung capacity, the vital capacity and the functional residual capacity were calculated.

The results were analyzed by statistical methods in order to determine the effects of various physical characteristics of the individual upon these 
volumes and to express these effects in the form of regression equations which may be used to estimate the "normal" lung volume and its subdivisions for a given individual. It was found that height or (height) ${ }^{3}$ is the best single standard of reference, but increased accuracy of prediction is gained by multiple regression equations including one or two standards of reference in addition to (height) ${ }^{3}$, with preference given to the index of build or chest girth and the index of fat rather than to actual or normal weight or to age.

For more limited ranges of height, linear equations which relate the lung volume and its subdivisions to standing height offer a convenient means of estimating normal values without much sacrifice of accuracy. Such equations are presented for two ranges of height, $140-160 \mathrm{~cm}$. and $160-190 \mathrm{~cm}$.

Semi-logarithmic equations which relate the logarithms of the lung volume and its subdivisions to standing height were also derived by statistical analysis of the data. While they offer no greater accuracy of prediction than the corresponding equations based upon (height) ${ }^{3}$ for the age and height range covered by the study, comparison with vital capacity data reported in the literature for younger children suggests that the semi-logarithmic equation may apply better to the larger range of ages covering early childhood to young adulthood.

In the resting recumbent position the relative proportions of the total lung capacity occupied by the inspiratory capacity and the expiratory reserve and residual volumes were found to be 63.9 , 17.0 and 19.1 per cent, respectively, in boys of 10 to 17 years as a group. An effect of age upon the relative proportions of the total volume occupied by the various subdivisions during those years is suggested by relatively lower values for the expiratory reserve and residual volumes at 13 and 15 years. Certain of the 13-, 14- and 15-year-old boys were found to have lower total lung capacities relative to their size than were found in younger and older boys.

\section{ACKNOWLEDGMENTS}

The authors wish to express their deep appreciation and thanks to Dr. D. B. Dill, formerly of the Fatigue Laboratory at Harvard University, and at present Scientific Director, Medical Division, Army Chemical Center, Md., at whose suggestion the study was undertaken, and to Dr. Sid Robinson of the Department of Physiology, Uni- versity of Indiana, who so kindly gave us the benefit of his experience with the methods.

\section{REFERENCES}

1. Morse, M., Schlutz, F. W., and Cassels, D. E., Relation of age to physiological responses of the older boy (10-17 years) to exercise. J. Appl. Physiol., 1949, 1, 683.

2. Metheny, E., Breathing capacity during the first decade of life. A review of the literature on techniques, standards and clinical implications. J. Pediat., 1941, 19, 841.

3. Metheny, E., Breathing Capacity and Grip Strength of Preschool Children. University of Iowa Studies in Child Welfare, Vol. XVIII, No. 2. Univ. of Iowa Press, Iowa City, 1940.

4. Turner, J. A., and McLean, R. L., Spirometric measurements of lung function in healthy children. Pediatrics, 1951, 7, 360.

5. Robinson, S., Experimental studies of physical fitness in relation to age. Arbeitsphysiol., 1938, 10, 251.

6. Lassen, H. C. A., Cournand, A., and Richards, D. W., Jr., Distribution of respiratory gases in a closed breathing circuit. I. In normal subjects. J. Clin. Invest., 1937, 16, 1.

7. Christie, R. V., The lung volume and its subdivisions. I. Methods of measurement. J. Clin. Invest., 1932, 11, 1099.

8. Standardization of definitions and symbols in respiratory physiology. Federation Proc., 1950, 9, 602.

9. Hurtado, A., and Boller, C., Studies of the total pulmonary capacity and its subdivisions. I. Normal, absolute and relative values. J. Clin. Invest., 1933, 12, 793.

10. Mainland, D., The Treatment of Clinical and Laboratory Data; An Introduction to Statistical Ideas and Methods for Medical and Dental Workers. Oliver \& Boyd, Ltd., Edinburgh, 1938, p. 204.

11. Herrald, F. J. C., and McMichael, J., Determination of lung volume: simple constant volume modification of Christie's method. Proc. Roy. Soc., London, 1939, 126B, 491.

12. McMichael, J., A rapid method of determining lung capacity. Clin. Sc., 1939, 4, 167.

13. Meneely, G. R., and Kaltreider, N. L., Use of helium for determination of pulmonary capacity. Proc. Soc. Exper. Biol. \& Med., 1941, 46, 266.

14. Gilson, J. C., and Hugh-Jones, P., The measurement of the total lung volume and breathing capacity. Clin. Sc., 1949, 7, 185.

15. Darling, R. C., Cournand, A., and Richards, D. W., Jr., Studies on the intra-pulmonary mixture of gases. III. An open circuit method for measuring residual air. J. Clin. Invest., 1940, 19, 609.

16. Campbell, J. A., and Hill, L., Concerning the amount of nitrogen gas in the tissues and its removal by breathing almost pure oxygen. J. Physiol., 1931, 71, 309. 
17. McCloy, C. H., Appraising Physical Status : the Selection of Measurements. University of Iowa Studies in Child Welfare, Vol. XII, No. 2. Univ. of Iowa Press, Iowa City, 1936, p. 106.

18. McCloy, C. H., Appraising Physical Status: Methods and Norms. University of Iowa Studies in Child Welfare, Vol. XV, No. 2. Univ. of Iowa Press, Iowa City, 1938, pp. 14, 34, 52.

19. Boothby, W. M., and Sandiford, R. B., Nomographic charts for calculation of metabolic rate by the gasometer method. Boston M. \& S. J., 1921, 185, 337.

20. DuBois, D., and DuBois, E. G., Clinical calorimetry. $\mathrm{X}$. A formula to estimate the approximate surface area if height and weight be known. Arch. Int. Med., 1916, 17, 863.

21. Goulden, C. H., Methods of Statistical Analysis. John Wiley \& Sons, Inc., New York, 1939, p. 211.

22. Aslett, E. A., Hart, P. D'A., and McMichael, J., The lung volume and its subdivisions in normal males. Proc. Roy. Soc., London, 1939, 126B, 502.

23. Stewart, C. A., The vital capacity of the lungs of children in health and disease. Am. J. Dis. Child., 1922, 24, 451.

24. Kelly, H. G., A Study of Individual Differences in Breathing Capacity in Relation to Some Physical Characteristics. University of Iowa Studies in Child Welfare, Vol. VII, No. 5. Univ. of Iowa Press, Iowa City, 1933.

25. Hurtado, A., Fray, W. W., Kaltreider, N. L., and Brooks, W. D. W., Studies of total pulmonary ca- pacity and its subdivisions. V. Normal values in female subjects. J. Clin. Invest., 1934, 13, 169.

26. Kaltreider, N. L., Fray, W. W., and Hyde, H. V., The effect of age on the total pulmonary capacity and its subdivisions. Am. Rev. Tuberc., 1938, 37, 662.

27. Rotta, A., and Guerrero, F., Estudios sopre la capacidad pulmonar. An. Fac. Cienc. Méd. (Univ. Lima), 1936, 19, 49.

28. Birath, G., Lung volume and ventilation efficiency. Changes in collapse-treated and non-collapse-treated pulmonary tuberculosis and in pulmonectomy and lobectomy. Acta. med. Scandinav., 1944, Supp. $154,1$.

29. Bateman, J. B., Studies of lung volume and intrapulmonary mixing: normal lung capacities. J. Appl. Physiol., 1950, 3, 133.

30. Goulden, C. H., Op. cit., p. 122.

31. Izzo, R. A., and Chiodi, H., A modified Christie method for residual air measurements. Am. J. M. Sc., 1943, 206, 190.

32. Meneely, G. R., and Kaltreider, N. L., The volume of the lung determined by helium dilution. Description of the method and comparison with other procedures. J. Clin. Invest., 1949, 28, 129.

33. McMichael, J., and McGibbon, J. P., Postural changes in the lung volume. Clin. Sc., 1939, 4, 175.

34. Whitfield, A. G. W., Waterhouse, J. A. H., and Arnott, W. M., The total lung volume and its subdivisions. A study in physiological norms. I. Basic data. Brit. J. Social Med., 1950, 4, 1. 